DOI: $10.17805 /$ trudy.2015.4.2

\title{
ТЕЗАУРУС РУССКОГО НАЦИОНАЛЬНОГО ХАРАКТЕРА
}

\author{
T. А. Горелова \\ (Московский гуманитарный университет)
}

Аннотация: В работе рассматривается структура тезауруса русского национального характера, определяются причины и механизмы его формирования. Просматриваются тенденции динамики этой структуры в настоящее время.

Ключевые слова: национальный характер, тезаурус, ценности, Россия, цивилизацзия, русский национальный характер.

\section{THESAURUS OF RUSSIAN NATIONAL CHARACTER}

\author{
T. A. Gorelova \\ (Moscow University for the Humanities)
}

\begin{abstract}
The article outlines the thesaurus structure of Russian national character, defining the causes and mechanism of its emergence. Looking at the dynamics of its change, we describe some trends relevant to its contemporary state.

Keywords: national character, thesaurus, values, Russia, civilization, Russian national character.
\end{abstract}

Глобальная «эпоха перемен» перекраивает этническую карту мира в соответствии с волей некоей надэтнической силы, действующей агрессивно и сознательно. Западная цивилизация, осуществившая грандиозный технологический скачок в процессе информационной революции, под руководством США выстраивает новый глобальный неоколониальный порядок подобно суперигроку, двигающему фигуры по «великой шахматной доске». Рациональности, холодному расчету и агрессивности этой силы может противостоять, с одной стороны, сознательное противодействие народов второго и третьего мира, а, с другой, духовное сопротивление, присущее стихийной этнической пассионарности того народа, 
который возглавит это сопротивление. У какого из крупных современных этносов - китайцев, индусов, русских или латиноамериканцев - есть такой потенциал, это интересный вопрос. Сам автор концепции пассионарности Л. Н. Гумилев считал, что следующий пассионарный толчок должен произойти на востоке среди монголоидных этносов. Но учитывая, что предыдущий западный проект колониальной системы в 1950-1960-е годы был разрушен странами советского блока во главе с СССР (Горелов, 2014: 24-28), не следует сбрасывать со счетов непредсказуемость русской цивилизации, ядро которой сформировано людьми определенного типа.

Отрицание некоей интуитивно ощущаемой этнической общности людей, проявляющейся в национальном характере, душе и духе данного народа, равносильно отрицанию существования нации как таковой. «Сущность всякой национальности, - писал В. Г. Белинский, - состоит в ее субстанции. Субстанция есть непреходимое и вечное в духе народа, которое, само не изменяясь, выдерживает все изменения, целостно и невредимо проходит через все фазисы исторического развития. Это зерно, в котором заключается всякая возможность будущего развития. Каждый народ имеет свою субстанцию, как и каждый человек, и в субстанции народа заключается вся его история и его различие от других народов» (Русская идея, 1992: 77).

По Э. Фромму, «подобно индивидуальному характеру, «социальный характер» можно определить как специфический способ, с помощью которого энергия направляется в определенное русло; отсюда следует, что если энергия большинства людей данного общества канализируется в одном и том же направлении, то они обладают одной и той же мотивацией, и, больше того, они восприимчивы к одним и тем же идеям и идеалам» (Фромм, 1992: 330), т. е. он проявляется как «ядро структуры характера, свойственное большинству представителей данной культуры» (там же). В таком понимании национальный характер предстает как единство различных уровней организации сознания и поведения людей - биологического, психологического, познавательного, социального и духовного, как некий «генетический» потенциал нации, который реализуется в определенных условиях ее жизни.

Психология XX в. пыталась реализовать программу определения индивидуального типа характера человека. Было создано несколько сотен психологических типологий характера. Методологически их можно разделить на два принципиально различных подхода - аналитический (или психология черт), стремящийся расщепить психику на более простые элементы, понять их работу и затем в типологии воссоздать их различия («Надо свести все черты характера к простейшим психическим элементам и к простейшим формам основных психологических законов, выяв- 
ляя при этом природу обнаруживаемых связей» (Полан, 1896: 64); и синтетический (или психология типов), стремящийся изначально «уловить» структуру всей конструкции психики и классифицировать их на основе качественного своеобразия этих центральных звеньев («Типологический подход заключается в глобальном восприятии личности и последующем сведении многообразия индивидуальных форм к небольшому числу групп, объединяющихся вокруг репрезентативного типа» (Мейли, 1975: 75)). Последующее развитие психологии как науки и как практической деятельности приводит к пониманию того, что отдельный человек - это микрокосм, которому присущи общечеловеческие черты и характеристики макрокосма, но их индивидуальное распределение имеет некоторые системные закономерности, во многом еще слабо осмысленные наукой.

Рисуя среднестатистический «психологический портрет» представителя нации в соответствии с синтетическим подходом, следует наметить некие его срезы, которые, с одной стороны, указывают структурную общность национального типа, но, с другой, именно в них следует искать индивидуальные «физиономические» отличия. Так, биолого-анатомический (черты лица, особенности движения и т. п.) и поведенческий (манеры) срезы демонстрируют зримую сторону национального характера: русский легко узнает соотечественника в европейском мегаполисе так сказать «по походке», даже не слыша звуков голоса. Психологический (черты характера и особенности интеллекта), социальный (типы взаимодействия в социуме) и особенно духовный (национальные ценности и смыслы) срезы не так очевидны и требуют специальных исследований и философских обобщений. Как следует из синтетического подхода, каждая из характерологических черт народа должна не только проявляться на указанных уровнях, но и соотноситься и взаимодействовать с другими чертами национального характера. Такая сложная картина взаимодействий требует особой комплексной методологии, которая ухватывала бы суммарную динамику множества процессов, причем как бы сверху, с позиции «наблюдателя со стороны». В качестве такой методологии можно выбрать тезаурусный подход Вал. А. и Вл. А. Луковых (Луков Вал., Луков Вл., 2013). Авторы метода предлагают его как способ построения субъектной ценностной картины мира отдельного человека. Но, на наш взгляд, сам подход гораздо шире и под субъектом можно понимать не только человека, но и социальные группы, в том числе народ.

Тезаурус («полнота», «накопление», «богатство», «достаточность», букв. «сокровище») как социокультурная система во взаимодействии с другими системами оформляет «жизненный круг» социального субъекта, воспроизводя иерархию мировоззрения, знаний, ценностей, представляя собой часть действительности, включенной в сферу его жизнедеятельно- 
сти. Системные характеристики тезауруса - полнота, существенность, систематичность, ориентирующе-ценностное назначение и избыточность как следствие такого свойства человека как непрерывная потребность в мыслительной деятельности (там же: 26-27). Таким образом, в тезаурусе как активном субъекте переплетается не только логически, но и ценностно иерархизированное гуманитарное знание. На наш взгляд, фактологическое субъект-объектное знание взаимодействует в тезаурусе с ценностным, образуя как бы два уровня освоения мира - более высокий ценностный и лежащий ниже познавательный.

Принципом построения тезауруса как системы является особая систематизация информации. Данные в тезаурусе выстраиваются не вертикально - от общего к частному, а горизонтально - от своего к чужому. Свое является центральным понятием, вбирая в себя общее. Общее как бы присваивается, встраиваясь в виртуальное свое. Все новое входит в тезаурус только как освоенное в той или иной мере. Поэтому основным «пространственно» дифференцирующим принципом тезауруса является триада «свое - чужое - чуждое», которая составляет «скелет» тезауруса. Устойчивый тезаурус обладает способностью активно поддерживать «свое» и тем самым выстраивает сам себя, навязывая свою инициативу субъекту-хозяину. Активность тезауруса способствует созданию особой независимой интеллектуально-культурной социальной системы, которая вмешивается в фильтрацию поступающей информации, блокируя, переиначивая или даже полностью исключая ту ее часть, которая разрушает целостность тезауруса.

Авторы идеи для обозначения базовых элементов тезауруса используют понятие «концепт», в котором отражен синтез образа и понятия. Часть устойчивых концептов, освоенных субъектом и способствующих замедлению изменений в структуре тезауруса, названы «константами».

Как любая система, тезаурус относительно устойчив, когда на него воздействует поток информации как знание, но теряет устойчивость при подрыве ценностных ориентаций. Особенностью тезауруса является тот факт, что его система ориентации опирается не столько на собственные внутренние качества, сколько на взаимодействия с однопорядковыми и направленными к тем же целям тезаурусами. Взаимодействие индивидов внутри социальных групп и обеспечивает устойчивость однородных тезаурусов или их сегментов. Возвращаясь к цели данной работы - осознать базовые элементы устойчивости структуры русского национального характера - отметим, что тезаурусный подход «схватывает» верхние этажи конструктивной системы («константы») характера - духовный и социальный срезы. «Вибрации» «верха» сказываются на всей длине здания национального характера. Именно об этом пойдет речь во второй части статьи. 
С помощью тезаурусного подхода попытаемся оценить трансформацию ценностных конструктов русского народа (как обобщенного субъекта) в XX в. ${ }^{1}$ Исторический путь, пройденный народом, и приобретенный на протяжении веков опыт в результате столкновения с различными проблемами и трудностями, откладывается в его социальной памяти и формирует ценностные установки его культуры. Человек рождается не в гомогенной в ценностном отношении среде. Он застает определенную систему ценностей, сформированную его культурой, так сказать тезаурусом более высокого порядка. Концепты ценностной системы нации, а в особенности, ее константы, на наш взгляд, формируются на пересечении базовых черт национального характера и устойчивых элементов мировоззрения ${ }^{2}$ народа. На эту связь характера и тезауруса народа указывали выдающиеся русские писатели и мыслители.

Широта русского характера - первое и основное объективное его свойство, фиксируемое не только многими русскими, но и западными мыслителями. «Широк человек, слишком даже широк, я бы сузил», - говорит герой Ф. М. Достоевского Дмитрий Карамазов. Находим у М. Ю. Лермонтова «... мир земной мне тесен» («Молитва»); у С. Т. Аксакова: «Тесно стало моему дедушке жить в Симбирской губернии» («Семейная хроника»); у М. Палеолога: «Нет излишеств, на которые не были бы способны русский мужчина или русская женщина, лишь только они решили “утвердить свою свободную личность” (Палеолог, 1991: 332). Тесно русскому человеку и в культуре, и в социуме из-за его широты.

Вероятно, есть несколько причин широты народного характера. Экологической причиной, которая основана на принципе единства человека и природы, является громада и бесконечность Великой русской равнины. Уместен вопрос Н. В. Гоголя, обращенный к русскому национальному характеру: «Что пророчит сей необъятный простор, здесь ли, в тебе ли не родиться беспредельной мысли, когда ты сама без конца?» По В. О. Ключевскому, те же условия пространства формировали и противоположную черту характера - стремление к объединению. Однообразие природных условий способствовало однообразным занятиям, что приводило к сходным обычаям и нравам, объединяя население огромной территории в один народ.

Широта характера имеет два социальных следствия: с одной стороны, русский человек не привязан к быту, дому, обществу (как писал Н.А.Бердяев в «Судьбе России», тип странника очень характерен для России, потому что он - самый свободный человек на земле; именно из преобладания этого типа рождается мятежная стихийность русской социальной и политической жизни: «страна духовного опьянения», «самозванцев и пугачевщины»), или более мягко: «Русский человек - дитя пространства, человек свободы и воли» (В. Личутин)); с другой стороны, социаль- 
ное единство, коллективизм также достигают максимального уровня и проявляются как соборность («Фактически я по поводу всего держу внутри себя собор со всеми, - пишет С. Н. Трубецкой, - и только то для меня истинно, достоверно всеобщим и безусловным образом, что должно быть таковым для всех» (Трубецкой, 1908: 13)).

Это двойственное следствие широты имеет и другое измерение: сохраняющаяся широта дает целостность, а широта треснувшая ведет к антиномичности характера, которая составляет вторую базовую черту русского характера. «Русский - человек крайностей. Это проявляется в антиномичности свойств русской души, лежащих... на поверхности душевной жизни: терпеливость - импульсивность, доверчивость - настороженность, пассивность - энтузиазм, лень - одержимость в труде» (Горелов, 2012: 47). Русская лень и способность на невероятно мощное трудовое усилие в краткий промежуток времени - с виду противоположности, но они хорошо сочетаются даже в одном человеке. Внутренняя противоречивость характера, которая проявляется на психологическом уровне (первые две пары антиномий), так и в социальной сфере (последующие пары), ведет к социокультурному расколу общества, начиная от раскола церковного и заканчивая расколом политическим.

Социальная «горизонтальная геометрия» русского характера связана с «вертикальной геометрией» его духа. Широта в духовном смысле охарактеризована Бердяевым как «безграничная свобода духа», что на философском языке означает способность к преодолению сложившихся форм и границ. Причем безграничность духа свободно перемещается по этой шкале как вверх к идеалу мессианизма и самопожертвования, так и вниз в глубины бездны - от мессианизма к апатии, от самопожертвования к преступности. С. Л. Франк обозначил эту вертикальную способность русского духа как то, он «не знает середины: либо все, либо ничего». Духовная организация такого национального характера вероятно возможна, если осознан и принят вектор движения, т.е. заданы смысл жизни и цель развития. Если же ориентиров нет, русский дух скатывается не в «духless» как западный человек, а в бездну аморальных поступков - пьянство, преступность, аборты, сиротство, вплоть до самоубийства (по количеству которых Россия занимает в начале XXI в. лидирующие позиции). Русская мораль, естественная и ситуационная, в некотором смысле является антиподом западной морали. Если западная мораль рациональна и унифицирована, то мораль в России основана на чувстве, а не на разуме, и личностно окрашена. Для того, кто понравился, русский сделает больше, чем положено по договору или закону. «Широта натуры русской» дает слишком большой диапазон - от благодати до аморальности.

Широта духа проявляется и как максимализм. Л. П. Карсавин отмечал, 
что русский человек не умеет быть «постепеновцем». Ему нужно быть идеалистом. Если идеал вдруг утрачен или осознана его неосуществимость, он сразу теряет всякую охоту жить и действовать. «Ради идеала он готов отказаться от всего, пожертвовать всем; усомнившись в идеале или его близкой осуществимости, являет образец неслыханного скотоподобия или мифического равнодушия ко всему» (Русская идея, 1992: 322). Очевидно, что иррациональность русского духа также происходит от первоначального и главного свойства национального характера - широты. Максимализм духа, без которого не одолеешь трудных препятствий, связан со слабостью формы, которая проистекает, по Н. А. Бердяеву, из нацеленности на то, чтобы превзойти, а не построить; и ведет к недостатку рационализма, осмотрительности, которые ограничивают тягу к трансцендированию. От недостатка рационализма - и невозможность понять Россию умом. Логика плохо сочетается с широтой, а рациональность - с ориентацией на «авось». Но русскому ближе именно свой национальный характер, поэтому Иванушка-дурачок, мифологический его носитель, всегда оказывается в русских сказках удачливее своих расчетливых братьев.

Пытаясь осознать особенности русского менталитета, еще митрополит Иларион в XI в. противопоставлял закон - благодати. Концепция закона как чего-то внешне налагаемого и гнетущего человека противоречит, по Илариону, новому времени, которое пришло с рождением Иисуса Христа и проявляется как благодать, ниспосылаемая человеку свыше. Б. П. Вышеславцев, продолжая идею Илариона, отмечает, что закон осуществляется через запреты и устрашения и обращается к интеллекту и воле. Причем, по его мнению, у современного человека произошло психологическое смещение и запрет вызывает противоположный эффект, который он назвал «законом иррационального противоборства» (Вышеславцев, 1994: 87). В современном обществе двигателем развития становится не запрет, а позитивное благодатное действие. Этика благодати обладает дополнительной энергией и выражает свободу, упование и любовь. Свойственное русскому национальному духу упование на благодать есть признак, с одной стороны, преобладающей иррациональности, женственности и чувственности в культуре, а, с другой, духовной зрелости национального характера и способности к духовным свершениям.

Третья базовая константа национального характера, которая антиномична его непривязанности к дому и месту, - потенциал коллективной жизни, проявляющийся в социальной сфере многовековым существованием общины и трудовой деятельностью в артелях, возвышается в духовной сфере до всечеловечности (Ф. М. Достоевский). Коллективная жизнь как бы уравновешивает стихийность нрава и помогает устоять при изменении условий жизни народа. И широта русской ментальности требует 
поделиться с другим благодатью, полученной свыше - невозможно быть счастливым в одиночку. По Бердяеву, всечеловечность, вселенскость русского человека непосредственно вытекает из глубины его национального духа и вмещает вселенскую соборность, которая базируется на единстве и коллективности сознания человечества. «Это русская идея, что невозможно индивидуальное спасение, что спасение - коммюнотарно, что все ответственны за всех... то, что Россия несет миру, прежде всего - братство людей и свобода духа» (Бердяев, 1994: 220, 235).

Таким образом, триединство базовых констант русского национального характера «широта проявления - антиномичность формы - потенциал коллективности» продуцируют духовную основу русского национального тезауруса. Широта характера определяет иррациональность и стихийность русского тезауруса. Антиномичность задает противоречивую форму структуры тезауруса, в котором динамика создается чередованием периодов единства и раскола ценностных ориентаций, а максимализм поднимает планку ценностей выше универсального уровня: от «не навреди» золотого правила этики до самопожертвования, от справедливости - до правдоискательства, от патриотизма - до мессианства, от коллективизма - до всечеловеческой соборности и т. д. В социальной сфере это глубинное противоречие национального характера проявляется в том, что самый безгосударственный народ строит самое большое государство - империю, дающую приют множеству народов разной веры и традиций (Н. А. Бердяев). «Русский человек идентифицирует себя с народом и страной, не видя смысла в своем существовании отдельно от них... Готовность к жертве живет в душе русского человека» (Ильинский, 2015: 230).

Национальный характер формирует подходящие для своего функционирования системы ценностей. Каждая ценность входит в структуру тезауруса или структуру культуры как целостного исторического типа, поэтому они цементируют общество, объединяют индивидов, группы, нации и в конечном счете все человечество в единую духовную суперсистему. По аналогии с биосферой как сферой жизни и ноосферой как сферой сознания можно говорить о существовании аксиосферы культуры. Продолжая экологическую аналогию с экосистемами, можно заметить, что система западного тезауруса устойчива только при условии экспансии собственных ценностей в другие сообщества (отсюда высокий уровень современной культурной агрессии Запада); китайский тезаурус уравновешивается, когда возвращает гармонию в традиционные ценности (китайцы это хорошо ощущают еще со времен Конфуция); слишком широкий диапазон констант определяет неустойчивость русского национального тезауруса, которая преодолевается только осознанием общенационального смысла и направления к цели. 
Очередной эксперимент, который проводит на себе русская цивилизация с конца XX в., раскрыв шлюзы для притока западных, претендующих на глобальный смысл, ценностей, сталкивает в русском национальном тезаурусе разные ценностные миры и стремится обесценить прежнюю культурную традицию, мировоззренческие и идеологические установки. Традиционные ценности коллективизма и самопожертвования, в прошлом связанные с христианской системой ценностей, а в недавнем прошлом - с нормами коммунистической морали, в последние двадцать лет вытесняются установкой на индивидуальный и групповой эгоизм как современную форму «разумного эгоизма», по которой всепоглощающее стремление к богатству, успеху и выгоде как бы выражают требования морали. Новая концепция российской аксиосферы создается под давлением новой экономики рынка, неолиберальной политики глобального неоколониализма, расширяющегося общества потребления и массовой культуры.

Современную ценностную ориентацию народа России можно оценить как «тезаурусный сдвиг»: в 1990-е годы произошли качественные сдвиги шкалы ценностей - ценности материального прагматического характера существенно потеснили ценности духовно-нравственного характера. Особенно заметны ценностные трансформации в молодом поколении. Межпоколенческое смещение ценностей указывает, по сути, направление социального развития общества. Сравнительное исследование мировоззренческих установок российского студенчества, проведенное группой социологов России, Белоруссии, Украины и Армении в 1991 и 2013 гг., показывает, что это новое «непоротое поколение» (как его называет автор статьи) двигается в направлении индивидуализма и стремления отгородиться от общественного долга (Овсянников, 2015: Электр. ресурс). Это поколение духовной апатии: если взять различия в суммарной доле всех индикаторов установок, приведенных в указанной выше работе, то получается суммарная активность мировоззрения поколения 1991 г. в среднем на 20\% выше, чем у поколения 2013 г. «Такое положение несет в себе угрозы социальной анемии, потери солидарности, очень опасной для России: снижение уз солидарности у нас всегда означает нарастание распрей и смут» (там же). Это подрастающее поколение 1990-х имеет глобальное сходство: не только в России, но и в других странах, индивидуализм, гедонизм, ориентация на потребление пришли на смену нацеленности на познание мира и заменили принцип духовного долженствования на примитивную установку: «я расплатился деньгами и никому ничего не должен». Будучи продуктом глобализации, это поколение, по мнению тех, кто оседлал глобализацию, призвано нести идеи гомогенизации мира и вширь, и вглубь. 
России, как и всему миру, навязываются рациональные и прагматические ценности западной цивилизации. В дальнем круге социального общения это неолиберальные ценности безграничной свободы тела и потребительские ценности купли-продажи всего того, что раньше продавать было нельзя, - обязательства данному слову, чести и т. д. Ценности ближнего круга также подверглись жесткой эрозии: не осуждается самоубийство - оно регламентируется через эвтаназию; разрушается традиционная семья - через однополые браки с возможностью усыновления (причем детей «завозят» как товар из других стран, поскольку уровень собственного воспроизводства стремится к нулю); нарушается традиционная межпоколенческая система воспитания детей - через ювенальную систему права. Цивилизация, технологически опережающая остальной мир на десятилетия, под видом передовых устремлений предлагает явно разрушительные антиценности. Существенной особенностью ценностного кризиса, переживаемого ныне российским обществом, является то, что он системный и проявляется как тотальное отчуждение человека: между поколениями, от властной элиты, от политического участия, от духовной заинтересованности в результате труда, от достоверной информации, от личной безопасности и т.д.

Возвращаясь к трансформации тезаурусной национальной структуры российского общества, отметим ее современные особенности. Во-первых, русский тезаурус продолжает сохранять состояние ценностной неустойчивости и хаотичности. Воздействие западной структуры ценностей, которая не только отказалась от гуманистической системы ценностей эпохи Просвещения (Панарин, 2002: 78-80), но, более того, в которой изменился сам закон их функционирования (Бодрийяр, 2012: 10-11), крайне пагубно для социальной эволюции человечества в целом. В сингулярности кризисной ситуации ценности приобретают функции аттракторов, втягивающих все общество в новое социокультурное состояние (Лапин, 1996: 4). В терминах концепции синергетической модели эволюции хаос предшествует скачку к более высокому состоянию структуры (в данном случае ценностной) или за ним следует деградация структуры к более низкому состоянию.

Во-вторых, широта русского национального характера создавала во все времена огромный культурный потенциал синтеза. Парадоксальность современной ситуации в том, что происходит не синтез, а ценностная поляризация населения в различных направлениях: люди, достигшие экономического и политического успеха - элита, явно на стороне западно-глобальных ценностных ориентаций (несмотря на озвучиваемые ими в прессе другие, в частности патриотические, мнения); основная масса русского населения исповедует традиционные (патриархальнокоммунистические) ценности; остальное население вернулось к 
религиозным системам ценностей, причем некоторые из них (например, ценности ислама) активно противопоставляются всем остальным.

B-третьих, общество потребления оказывает давление на константы национального характера, а те, в свою очередь, реагируют по-разному. Широта характера впускает в ценностное поле самые разные установки идеологические, религиозные, социокультурные. Их «просеивание» происходит не сразу, а кристаллизации можно ожидать через 2-3 десятка лет (как было после революции 1917 г.). Иррациональность характера и упование на благодать также не способствуют переориентации на западные рациональные установки и прагматические ценности. Основной удар западной системы ценностей пришелся на русский коллективизм, который не только в виде соборности сознания, но и как общинная жизнь (артель на производстве, община как коллективная жизнь в деревне) не прерывался в России. Утрата осмысленной цели коммунальной жизни приводит к тому, что цели, особенно у молодежи, становятся случайными и тогда возникают разнообразные «тусовки» - клубные, футбольные и т. п., а в худшем случае - преступные.

Широта, антиномичность и стихийность - воспроизводящиеся и устойчивые черты русского национального характера - возникают в результате взаимодействия генетических особенностей русского народа, природных условий его жизни, географического положения страны, сложившихся в веках культурных традиций и поэтому их невозможно как отпрыск у растений взять и пересадить в другие условия. Ключевой особенностью России в XXI в., как было и раньше, остается то, что даже заимствованное она перерабатывала и после переходного периода всегда творила собственный национальный тезаурус, потому что он как ценностно-мировоззренческое проявление характера народа создает ситуацию, интуитивно наиболее подходящую для жизни каждого представителя данного народа: «...и дым отечества нам сладок и приятен».

Двойственность и поляризованность русского национального характера предопределяют русскую историю и социальную жизнь. Русский мир един в годину испытаний, но чаще это расколотый мир. Церковный раскол XVII в. разделил Россию на «старообрядцев» и «никониан» В XVIII в. Петр I раскалывал русский мир реформами и технологиями по западному образцу. В XIX в. раскол осознавался как разделение на «западников» и «славянофилов», а в XX в. - на «белых» и «красных», на патриотов и либералов, на анархистов и государственников ${ }^{3}$. Полярность, о которой писал Н. А. Бердяев, и есть результат широты русского национального характера, в которую укладываются духовные движения, противоположные по своей направленности.

Механизм формирования русской истории и социальной жизни - 
от единства к расколу и новый возврат единства - в принципе в явной форме отражает синергетическую парадигму развития системы - от порядка к точке бифуркации и следующему за ней хаосу, а затем к новому порядку. Синергетическая модель развития предполагает фиксацию особых состояний систем - нелинейность развития, переломные моменты (точки бифуркации), аттрактивность, чередование упорядоченных и хаотических состояний, скачкообразные переходы от первых ко вторым, диссипативные структуры (новые упорядоченные состояния систем). В социокультурных исследованиях синергетика акцентирует внимание на тех аспектах социальной реальности, которые «в классических теориях рассматриваются, как второстепенные и случайные, хотя в кризисной ситуации, особенно в момент бифуркации, они могут сыграть решающую роль в ее исходе. Социум содержит в себе различные латентные сценарии будущего. Какой конкретный вариант актуализируется в критической точке бифуркации, предсказать невозможно. Однако, исследуя социальное поле, можно найти перспективные линии социальной эволюции, из которых одна в будущем станет эмпирической реальностью (структуройаттрактором)» (Ельчанинов, 2005: 34, 38). Аттракторы - это информационные структуры, вокруг которых открытые системы движутся и самоорганизуются, т. е. к которым они «притягиваются». Аттрактор - цель и форма системы. Исследователи выделяют множество аттракторов, но все состояния могут быть сведены к набору простых организующих структур. Возвращаясь к теме статьи, следует отметить, что национальный характер и является одним из таких аттракторов, который «притягивает» определенные исторические события. Иными словами, русская история не могла быть другой именно в силу особенностей русского национального характера.

\section{СПИСОК ЛИТЕРАТУРЫ}

Бердяев, Н. А. (1994) Русская идея. Основные проблемы русской мысли XIX века и начала XX века // Русская идея. В кругу писателей и мыслителей русского зарубежья : в 2 т. М. : Искусство. Т. 2. 684 с. С. 204-286.

Бодрийяр, Ж. (2012) Прозрачность зла. М. : Добросвет. 260 с.

Вышеславцев, Б. П. (1994) Этика преображенного Эроса. М. : Республика. 368 с.

Горелов, А. А. (2012) История русской культуры. 2-е изд. М. : Юрайт. 387 c.

Горелов, А. А. (2014) Глобальный неоколониализм и русская идея. М. : ЛЕНАНД. 256 с.

Ельчанинов, М. С. (2005) Социальная синергетика и катастрофы России в эпоху модерна. М. : КомКнига. 240 с. 
Ильинский, И. М. (2015) Великая Отечественная: Правда против мифов. М. : Изд-во Московского гуманитарного университета. 321 с.

Ламажаа, Ч. К. (2012) Тезаурусный подход для тувиноведения // Знание. Понимание. Умение. № 2. С. 38-45.

Ламажаa, Ч. К. (2013) Тувиноведение: Новые горизонты. М. : Книжный дом «Либроком». 184 с.

Лапин, Н. А. (1996) Динамика ценностей населения реформируемой России. М. : Едиториал ; УРСС. 126 с.

Луков, Вал. А, Луков, Вл. А. (2013) Тезаурусы II: Тезаурусный подход к пониманию человека и его мира. М. : Национальный институт бизнеса. 640 c.

Мейли, Р. (1975) Структура личности // Экспериментальная психология. М. : Прогресс. Вып. 5. С. 75-81.

Овсянников, А. А. (2015) Экзамен по мировоззрению [Электронный peсурс] // Независимая газета. № 88 (6419) от 28 апреля. URL: http://www. ng.ru/scenario/2015-04-28/9_exam.html (дата обращения: 12.05.2015).

Палеолог, М. (1991) Царская Россия накануне революции. М. : Политиздат. 493 с.

Полан, Ф. (1896) Психология характера / пер. с фр. и ред. Р. И. Сементковского. СПб. : Изд-во Ф. Ф. Павленкова. 208 с.

Панарин, А. С. (2002) Православная цивилизация в глобальном мире. М. : Алгоритм. 496 с.

Русская идея. Антология (1992). М. : Республика. 496 с.

Трубецкой, С. Н. (1908) О природе человеческого сознания // Собрание сочинений Кн. Сергея Николаевича Трубецкого. М. : Тип. Лисснера и Собко. Т. 2. 265 с.

Фромм, Э. (1992) Душа человека. М. : Республика. 429 с.

Горелова Татьяна Анатольевна - доктор философских наук, профессор кафедры философии, культурологии и политологии Московского гуманитарного университета. Адрес: 111395, Россия, г. Москва, ул. Юности, д. 5. Тел.: +7 (499) 374-55-11. Эл. адрес: gorelovata@mail.ru

Gorelova Tatyana Anatolievna, Doctor of Philosophy, Professor, Department of Philosophy, Culturology and Politology, Moscow University for the Humanities. Postal address: 5 Yunosti St., 111395 Moscow, Russian Federation. Tel.: +7 (499) 374-55-11.E-mail: gorelovata@mail.ru 


\section{ПРИМЕЧАНИЯ}

${ }^{1}$ Удачный пример такой тезаурусной реконструкции видим на примере тувинского народа: Ламажаа, 2012, 2013.

${ }^{2}$ Марксистская формула «мировоззрение есть синтез мироощущения и миропонимания» как никакому другому подходит русскому народу (причем доля мироощущения явно преобладает).

${ }^{3}$ Главный герой романа «Преступление и наказание» Ф. М. Достоевского Раскольников символически олицетворяет этот русский раскол. Раскалывая топором голову старушки-процентщицы, он раскалывает свою жизнь на два периода: период «до преступления», когда он мучился самоутверждением («...тварь я дрожащая, или право имею»), и период «после...», когда муки совести и меч наказания опустили героя в бездну... но и дали затем душе воскреснуть - в этом выходе русскость характера Раскольникова. 